\title{
Cost Minimization Model of Gas Transmission Line for Indonesian SIJ Pipeline Network
}

\author{
Septoratno Siregar ${ }^{1,3}$, Edy Soewono ${ }^{2,3}$, Daniel Siregar ${ }^{3}$, \\ Satya A. Putra ${ }^{4} \&$ Yana Budicakrayana ${ }^{4}$ \\ ${ }^{1}$ Department of Petroleum Engineering, Institut Teknologi Bandung \\ ${ }^{2}$ Department of Mathematics, Institut Teknologi Bandung \\ ${ }^{3}$ Research Group for Industrial \& Applied Mathematics, Institut Teknologi Bandung \\ ${ }^{4}$ PERTAMINA
}

\begin{abstract}
Optimization of Indonesian SIJ gas pipeline network is being discussed here. Optimum pipe diameters together with the corresponding pressure distribution are obtained from minimization of total cost function consisting of investment and operating costs and subjects to some physical (Panhandle A and Panhandle B equations) constraints. Iteration technique based on Generalized Steepest-Descent and fourth order Runge-Kutta method are used here. The resulting diameters from this continuous optimization are then rounded to the closest available discrete sizes. We have also calculated toll fee along each segment and safety factor of the network by determining the pipe wall thickness, using ANSI B31.8 standard. Sensitivity analysis of toll fee for variation of flow rates is shown here. The result will gives the diameter and compressor size and compressor location that feasible to use for the SIJ pipeline project. The Result also indicates that the east route cost relatively less expensive than the west cost.
\end{abstract}

\section{$1 \quad$ Introduction}

With large natural gas resources and the increase demand of domestic gas consumption in Indonesia, the need to extend the existing pipeline network and to build new pipelines connecting several resources and consumers has been growing significantly in the last decade. In order to connect the gas fields to the costumers which are normally several hundred kilometers away, it is very important to build an integrated and efficient transmission pipeline. The role of optimization techniques is very crucial to minimize the investment and operating cost.

The transmission network being considered here is approximately $1200 \mathrm{~km}$ long connecting two islands in Indonesia. This Pipeline is estimated to deliver about 800 MMSCFD gas from 2 sources with two possible choices of routes, which are west route and east route. This network is described in section 2. The parameters being optimized here are pipe diameters, pressure at each node and compressor horse power. 
Several commercial softwares being used in gas industries are not directly built on the basis of cost optimization. Here we use mathematical model for the pipeline cost as a function of pipe diameters and pressures, which satisfy some physical constraints. Relevant technical, economical and physical aspects related to investment and operating costs are taken into account. There are several literatures on pipe line optimization (see for example in $[1,2,3]$ ), most of them use simplified model either in the construction of cost function or in the constraints. Recently a complete cost model which is suitable for Indonesian gas fields was proposed in [4]. This model turns to be useful both for transporter companies and gas field owners. Applications of the model in different fields and different conditions could be seen in $[5,6]$. This cost model is presented in section 4. This cost function will be the objective function for our optimization. In section 3, we review Panhandle A and Panhandle B equations describing the flow equation in each segment of pipes. This flow equation together with maximum pressure in each segment and maximum discharge pressure of compressors will function as constraints for the minimization techniques which are described in section 6 . Wall thickness calculation which is related to the strength of the pipe is discussed in section 5 .

The optimum diameters that are obtained from the optimization process will be adjusted to the nearest sizes which are available in the market. The safety factor of the pipeline will be calculated by determining the pipe wall thickness using ANSI B.31 standard. These results are also adjusted to the real sizes available in the market.

\section{Description of SIJ Network}

SIJ pipeline transmission network is to be chosen between two possible (west and east) routes, both connecting the inlet point A with the outlet point SN as shown in figure 1 . The total length of each route is about $1200 \mathrm{~km}$. Only the segment OF-SN lie off-shore and the rest of the network lies on-shore. In order to anticipate large pressure drop, compressor are planned to be located in four positions.

Elevation in each segment due to bottom topography is shown in figures 2 and 3 . These elevations could contribute significantly to the pressure drops along the transmission line and will be taken into account in the computation in the later sections. The objective here is to find optimum pipe diameters for each route taking into account some necessary constraints. 


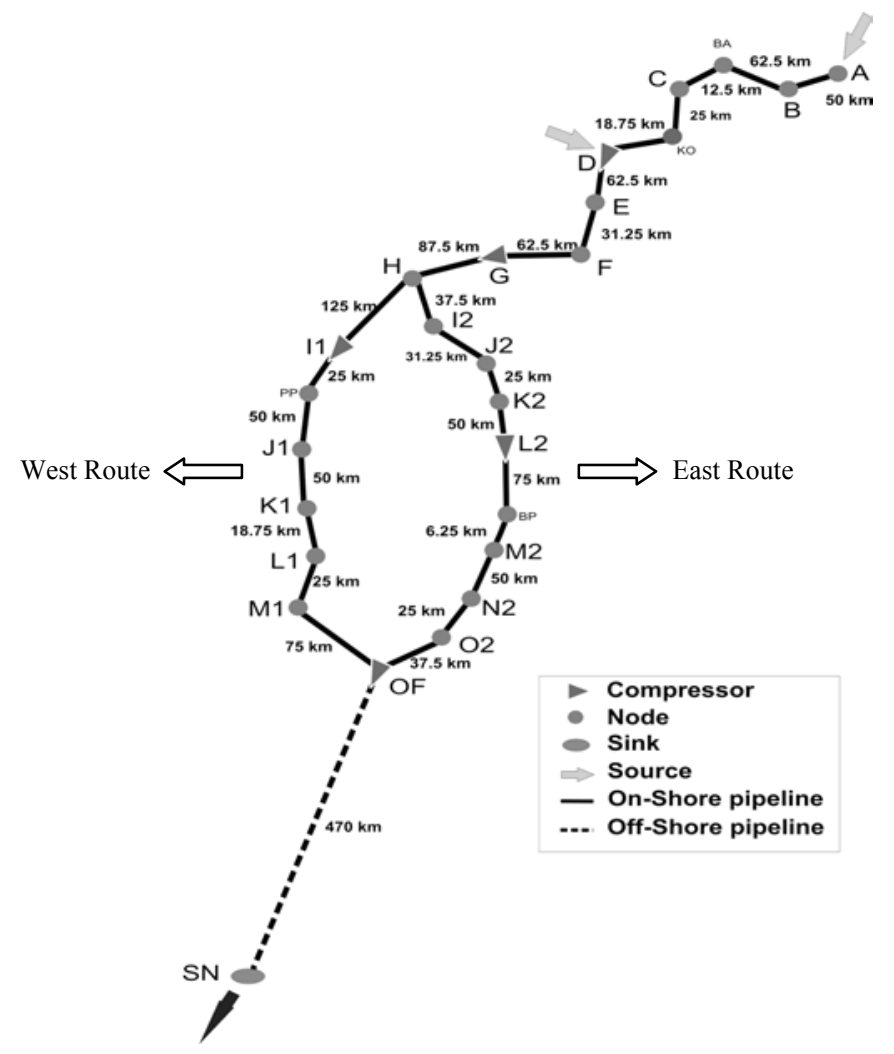

Figure 1 Map of the network.

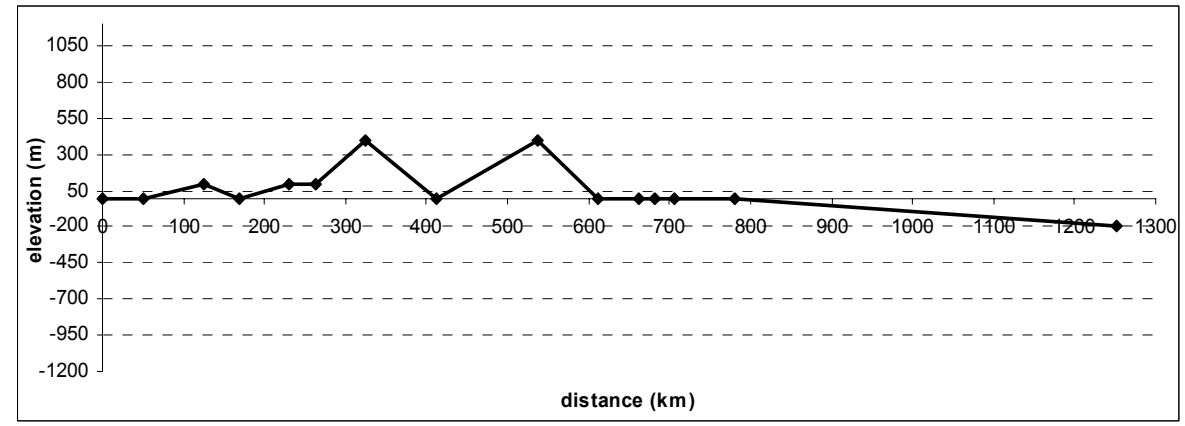

Figure 2 Elevation map (west route). 


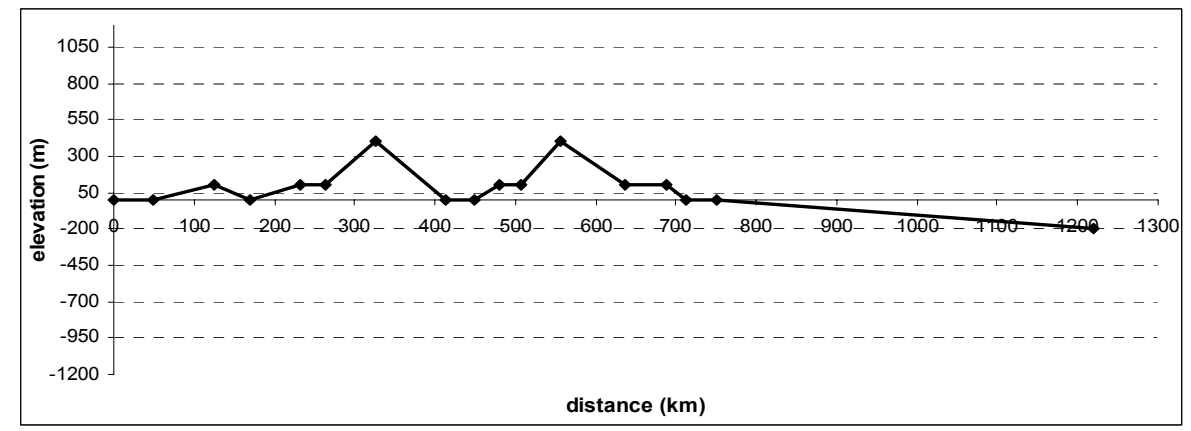

Figure 3 Elevation map (east route).

\section{$3 \quad$ Pipe Flow Equation}

Flow equation in a single segment of transmission pipeline is generally derived from the steady state condition of the energy balance equation, taking into account the empirical friction factor .The equation is written in term of pressure gradient as follows [7]

$$
\frac{d p}{d l}=\frac{g}{g_{c}} \rho \sin \theta+\frac{f \rho v^{2}}{2 g_{c} d}+\frac{\rho v d v}{g_{c} d l},
$$

where

$$
\begin{array}{ll}
f & =\text { friction factor } \\
\theta & =\text { angle of elevation }
\end{array}
$$

Through out this paper we consider the case of steady state flow; therefore equation (1) is reduced to steady state flow equation

$$
\frac{d p}{d l}=\frac{g}{g_{c}} \rho \sin \theta+\frac{f \rho v^{2}}{2 g_{c} d} .
$$

Here we assume that the adiabatic condition prevails and temperature through out the pipe is constant. Friction between gas and inside wall of the pipe will cause a loss of mechanical energy during the flow. This energy loss depends on the viscosity of the gas and the roughness of inside wall. The friction factor depends also on the flow rate of the gas and the pipe diameter. Two models of friction factor are used here, which are Panhandle A and Panhandle B, as shown in equation (3) and (4),

$$
f=\frac{0.085}{N_{\mathrm{Re}}^{0.147}}
$$




$$
f=\frac{0.015}{N_{\mathrm{Re}}^{0.0392}}
$$

respectively. Note that the flow equation (2) will function as a constraint relating pressure and diameter in each segment of pipe.

\section{Cost Model Structure}

In this section the construction of the total cost model adopted from [4] will be discussed. This total cost will be used as the objective function for the optimization process. The cost is separated into two parts, the (total) pipe cost and the (total) compressor cost as follows

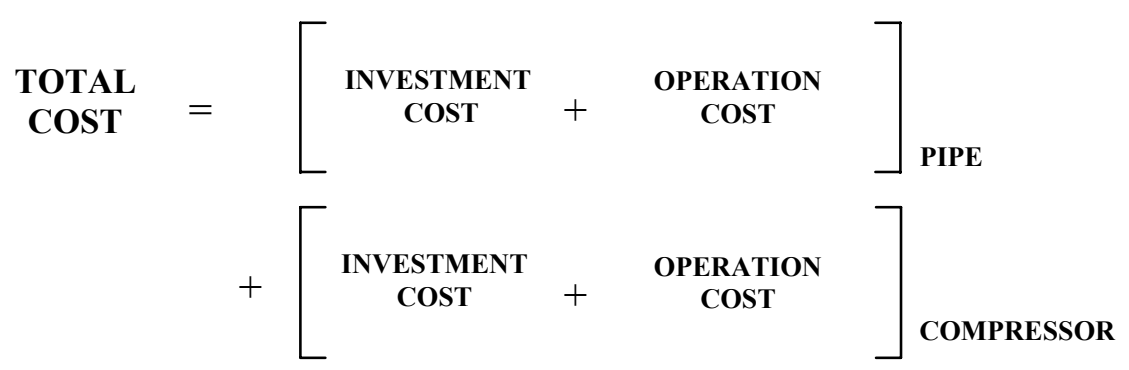

with some assumptions ,

a) gas in the pipeline is single-phase flow

b) gas flow in the pipeline is steady state

c) gas temperature along each segment of pipe is constant

d) gas temperature does not change after coming out of compressor

e) gas deviation factor $(Z)$ along each segment of pipe is constant and does not change after coming out of compressor

f) compressor type is centrifugal

g) tax, insurance, and other economic calculations are excluded.

\section{Investment Cost}

Here a uniform capital recovery is used for annual investment cost. The formula is given as follows

$$
A=P \frac{(1+r)^{n} r}{(1+r)^{n}-1}
$$


where

$$
\begin{array}{ll}
A & =\text { uniform annual capital cost } \\
P & =\text { present value of total investment cost } \\
r & =\text { annual interest rate } \\
n & =\text { life time of the equipment }
\end{array}
$$

\section{Investment Cost for Pipeline}

The total investment cost for a segment of pipe is given as follows

$$
\text { Cpipe }=(1+R p) C p L^{l} d^{m}
$$

where

$$
\begin{array}{ll}
\text { Cpipe } & =\text { pipe investment cost (US\$) } \\
R p & =\text { ratio between pipe installation cost and the pipe price itself } \\
C p & =\text { unit price of pipe (US\$/ft.inch), obtained from available data } \\
L & =\text { length of pipe (feet) } \\
d & =\text { diameter of pipe (inch) } \\
l, m & =\text { non-linearity constants obtained from regression. }
\end{array}
$$

The total investment cost for piping consists of pipe material, and installation cost. The annual cost based on capital recovery approach as indicated in equation (5) is

$$
C I P=\frac{r(1+r)^{n}(1+R p) C p L^{l} d^{m}}{(1+r)^{n}-1}
$$

where

$$
\begin{array}{ll}
C I P & =\text { annual investment cost of pipe (US\$/year) } \\
r & =\text { annual interest rate }
\end{array}
$$

\section{Compressor Investment Cost}

Investment cost of compressor is given by the following model

where

$$
\text { Ccomp }=\text { Chp } g h p^{b}
$$

$$
\begin{array}{ll}
C h p & =\text { compressor price }(\mathrm{US} \$ / \mathrm{hp}) \\
g h p & =\text { compressor power }(\mathrm{hp}) \\
b & =\text { non-linearity constant obtained from regression. }
\end{array}
$$


The compressor is centrifugal type. Based on the above assumptions, the power of compressor can be written as

$$
g h p=\frac{6250}{2061} \frac{Q \operatorname{PbTZ}\left(\left(\frac{P_{2}}{P_{1}}\right)^{\left(\frac{k-1}{k E p}\right)}-1\right) k}{T b(k-1)}+b l+s l
$$

where

$$
\begin{array}{ll}
Q & =\text { inlet gas flow-rate for the compressor (MMscfd) } \\
P b & =\text { base pressure }(\mathrm{psia}) \\
\mathrm{Tb} & =\text { base temperature }\left({ }^{\mathrm{O}} \mathrm{R}\right) \\
T & =\text { gas temperature }\left({ }^{\circ} \mathrm{R}\right) \\
Z & =\text { gas deviation factor } \\
P_{1} & =\text { inlet pressure (psia) } \\
P_{2} & =\text { outlet pressure (psia) } \\
k & =\text { adiabatic exponent } \\
E p & =\text { efficiency of compressor }(\%) \\
\mathrm{bl}, s l & =\text { bearing losses and seal losses. }
\end{array}
$$

The total investment cost for compressor is obtained as follows

$$
\text { Ccomp }=\operatorname{Chp}\left(\frac{6250}{2061} \frac{Q \operatorname{PbTZ}\left(\left(\frac{P_{2}}{P_{1}}\right)^{\left(\frac{k-1}{k E p}\right)}-1\right) k}{T b(k-1)}+b l+s l\right)^{b}
$$

We obtain the annual investment cost of compressor, CIC in US\$/year as follows 


$$
C I C=\frac{r(1+r)^{n}}{(1+r)^{n}-1} C h p\left(\frac{6250}{2061} \frac{Q P b T Z\left(\left(\frac{P_{2}}{P_{1}}\right)^{\left(\frac{k-1}{k E p}\right)}-1\right) k}{T b(k-1)}+b l+s l\right)^{b}
$$

\section{Pipeline Operating Cost}

The annual operating cost of pipeline is assumed to be proportional to the pipe investment cost as follows

$$
\text { OCpipe }=\frac{r(1+r)^{n}(1+R p) C f p C p L^{l} d^{m}}{(1+r)^{n}-1}
$$

where

$$
\begin{aligned}
& \text { Ocpipe }=\text { pipe operating cost }(\mathrm{US} \$ / \text { year }) \\
& C f p \quad=\text { fraction, a ratio of pipe operation cost to investment cost. }
\end{aligned}
$$

\section{Compressor Operating Cost}

Factors affecting the compressor operating cost are electricity cost for compressor operation (if electricity is used), maintenance cost, and other costs involved in compressor system.

The operating cost is proportional to the electricity cost, as follows

$$
\text { OCcomp }=x \text { Lstr }
$$

with $x>1$ and Lstr represents the electricity cost. For convenience, $x$ is written as

$$
x=1+\text { Copcomp }
$$

with Copcomp represents a fraction of compressor operating cost excluding its electricity cost. The compressor operating cost can be written as

$$
\text { OCcomp }=(1+\text { Copcomp }) \text { Lstr. }
$$

To obtain the electricity cost, the unit used in equation (8) is converted from horsepower to Kwh. So we have 


$$
L s t r=\frac{1}{8760}\left(19809.32047 \frac{Q P b T Z\left(\left(\frac{P_{2}}{P_{1}}\right)^{\left(\frac{k-1}{k E P}\right)}-1\right) k}{T b(k-1)}+6532.321518(b l+s l)\right) C e H y
$$

where

$$
\begin{aligned}
& \text { Ce } \quad \text { : electricity cost }(\mathrm{US} \$ / \mathrm{Kwh}) \\
& H y \quad \text { : operating compressor hours in a year. }
\end{aligned}
$$

\section{Toll Fee}

Toll fee is a service fee for delivering a unit of gas through a segment of pipeline. Toll fee can be charged per unit length (US\$ $/ \mathrm{MSCF} / \mathrm{km})$ or for a certain distance (\$/MSCF). Due to the effect of "economic of scale", toll fee is usually charged on distance basis. An illustration for calculating the toll fee is presented as follows.

a) Consider $\mathrm{N}$ segment transmission pipeline, then we have

$$
\begin{aligned}
\text { CIP } & =\text { CIP }_{1}+\text { CIP }_{2}+\ldots+\text { CIP }_{N} \\
\text { OCpipe } & =\text { OCpipe }_{1}+\text { OCpipe }_{2}+\ldots+\text { Ocpipe }_{N} .
\end{aligned}
$$

b) Gas that flows along the pipeline which is located after compressor is influenced by the compressor power, no matter how small it is. Due to this fact, we will add the CIC and OCcomp costs to each segment of pipe that is influenced by the compressor based on the length of the pipe. Thus, we have

$$
\begin{gathered}
\text { CIC }_{i}=\frac{L_{i}}{L f} \text { CIC, } \\
\text { OCcomp }_{i}=\frac{L_{i}}{L f} \text { OCcomp }
\end{gathered}
$$

with $L_{i}$ as the length of a segment of pipe which is located after compressor, and $L f$ as the total length of all pipes which are located after compressor.

c) Toll fee for each segment of pipe is 


$$
T F_{i}=\frac{C I P_{i}+\text { OCpipe }_{i}+\text { CIC }_{i}+\text { OC }_{\text {comp }}}{Q_{i} \times 365 \times 1000}
$$

with

$$
T F_{i}=\text { toll fee on segment of }-I(\mathrm{US} \$ / \mathrm{MSCF}) .
$$

Note that in practice the location of compressors represented by the parameters $L_{i}$ could be taken as optimizing parameters.

\section{Wall Thickness Calculation for Transmission Pipe}

Wall thickness calculation of the pipeline is obtained by using ANSI B 31.8 standard [10]. This standard is considering some factors, such as pipe design, diameter, pressure and the type of the pipe. The Equation of the wall thickness is given as

$$
t=\frac{P \cdot d_{0}}{2 \cdot(F \cdot E \cdot T \cdot S)}
$$

with :

$$
\begin{aligned}
& t=\text { wall thickness (inch) } \\
& P=\text { pressure (psia) } \\
& d_{0}=\text { outside diameter (inch) } \\
& S=\text { minimum pipe strength (psi) } \\
& F=\text { design factor } \\
& E=\text { join factor } \\
& T=\text { temperature derating factor. }
\end{aligned}
$$

Design factor depends on the location of the pipe. Some type of design factor can be seen below.

\begin{tabular}{|c|c|c|}
\hline Class & Design Type & Design Factor \\
\hline 1 & Oil and gas field or unpopulated area & 0.72 \\
2 & Semi-developed area, minimum facility & 0.6 \\
3 & Compressor station area. & 0.5 \\
4 & Commercials area & 0.4 \\
\hline
\end{tabular}

Join factor is the parameter that depends on pipe material. The value of the join factor is 
1.00 for seamless, ERW pipe,

0.80 for furnace lap and electrical fusion welded pipe,

0.60 for furnace butt welded pipe.

Temperature derating factor is a measurement of temperature's effect to the pipe material. This value gives the relation between the temperature and its impact to the pipe material. The value of this coefficient is given in the table below.

\begin{tabular}{|c|c|}
\hline Temperature $\left({ }^{\mathbf{0}} \mathbf{F}\right)$ & Derating Factor \\
\hline$-20^{\circ}-250^{\circ}$ & 1.000 \\
$300^{\circ}$ & 0.967 \\
$350^{\circ}$ & 0.933 \\
$400^{\circ}$ & 0.900 \\
$450^{\circ}$ & 0.867 \\
\hline
\end{tabular}

\section{Optimization Method}

Here we minimize an objective (Total Cost) function, which is nonlinear subject to a set of constraints consisting nonlinear equations and inequalities. We denote the objective function by $C(X)$ and the constraints $K_{j}(X)=0, j=1 . . J_{1}, K_{j}(X) \leq 0, j=J_{1} . . J_{2}$, where the components of $X$ are pipe diameters, gas pressures and compressor horse power, the equality constraints are the flow equations in each segment of pipes, and the inequality constraints are the maximum pressure conditions of pipes which represent the strength of the pipes. Note that the linear technique approach (see for example in $[1,2])$ is no longer workable in this model since high non-linearity terms involve in objective function as well as in constraints. Other approach using heuristic techniques were also done (see in $[8,9])$. The continuous approach being used here is chosen to accommodate more complicated physical condition such as surface elevation and if necessary the change of temperature can also be included.

From a given initial condition $X_{0}$, we select the direction, which gives the largest decrease of the cost. This direction is based on the Generalized SteepestDescent which is given by the gradient of each constraint $\left(\sum_{j=1}^{J_{1}} \alpha_{j} \nabla K_{j}\left(X_{n}\right)\right)$.

The procedure for constrained minimization is given as follows

$$
\left.\frac{d X}{d t}=-\nabla C(X)+\sum_{j=1}^{J_{1}} \alpha_{j} \nabla K_{j}(X)\right]
$$


where $t$ is iteration parameter and $\alpha_{j}$ has to satisfy the system of linear equations

$$
\sum_{j=1}^{J_{1}} \alpha_{j} \nabla K_{j}(X) \circ \nabla K_{i}(X)=\nabla C(X) \circ \nabla K_{i}(X), i=1 . . J_{1} .
$$

The Fourth Order Runge Kutta method is then applied to the dynamical equation (19) to produce the optimum result. Below is the algorithm for the computational process.

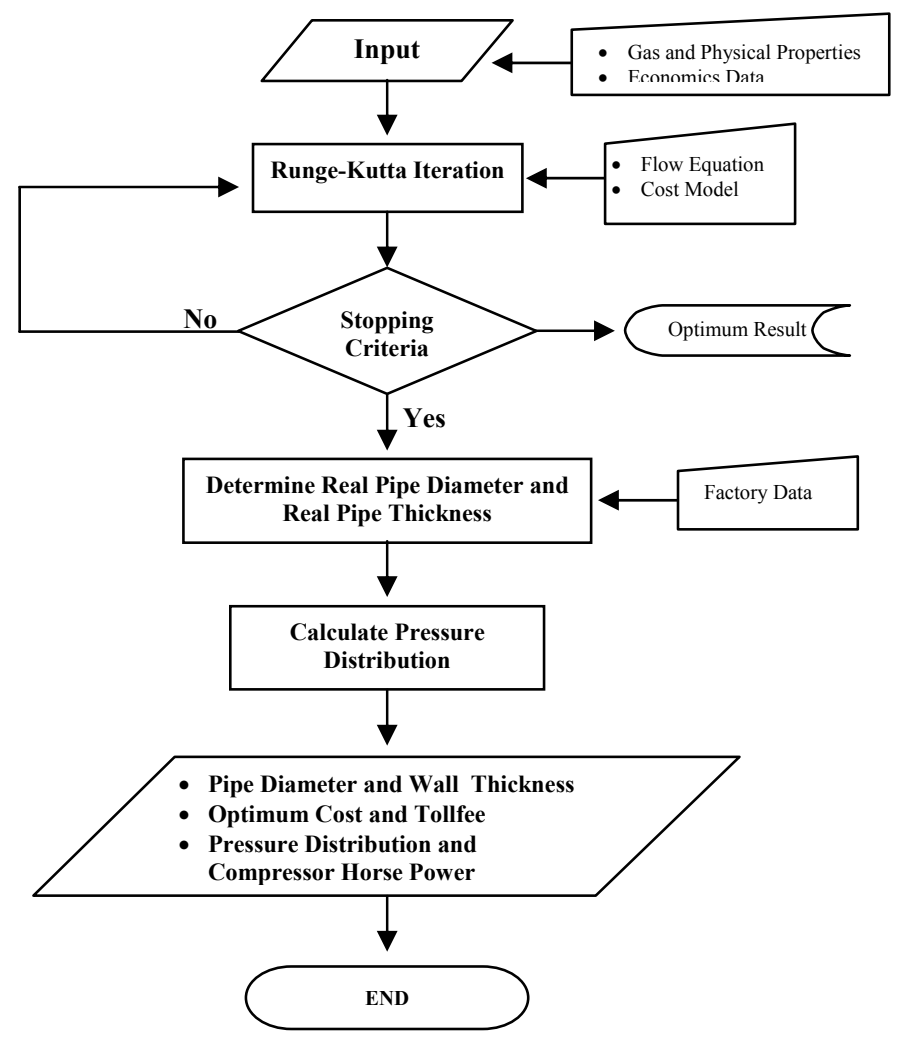

Figure 4 Numerical computation flow chart. 


\section{$7 \quad$ Numerical Results and Analysis}

Here we present numerical result for the SIJ pipeline transmission network. The set of data that is used in the computation is given in table 1 .

\begin{tabular}{|c|l|c|}
\hline Symbol & Parameter & Value \\
\hline$C_{e}$ & Electricity cost & $0.03 \mathrm{US} \$ \mathrm{kWh}$ \\
\hline$H_{y}$ & Time operation & $8760 \mathrm{hours}$ \\
\hline$C_{p}$ & Cost for a pipe / diameter / length & $0.569 \mathrm{US \$} / \mathrm{in} / \mathrm{ft}$ \\
\hline$L_{f p}$ & $\begin{array}{l}\text { Pressure fraction loss caused by valve, } \\
\text { bend, fitting, etc. }\end{array}$ & 0.35 \\
\hline$E_{p}$ & Compressor efficiency & 0.9 \\
\hline$R_{p}$ & $\begin{array}{l}\text { Comparison between installation cost and } \\
\text { pipe cost }\end{array}$ & $\begin{array}{c}\text { Onshore }: 1.4 \\
\text { Offshore: } 3\end{array}$ \\
\hline$C_{f p}$ & Yearly maintenance cost & 0.2 \\
\hline$S l$ & Sealing losses & $20 \mathrm{hp}$ \\
\hline$B l$ & Bearing losses & $30 \mathrm{hp}$ \\
\hline$R$ & Annual interest rate & $12 \%$ \\
\hline$C_{H P}$ & Compressor cost / horse power & $2000 \mathrm{US} \$ / \mathrm{hp}$ \\
\hline$F$ & Design factor & 0.6 \\
\hline$E$ & Join factor & 0.8 \\
\hline$T$ & Temperature derating factor & 1 \\
\hline$S$ & Minimum pipe strength & $65000 \mathrm{psi}$ \\
\hline & Pipe price & 0.617 \\
\hline$S G g$ & Gas Specific Gravity & 0.8 \\
\hline$Z$ & Z factor & $125^{\circ} \mathrm{F}$ \\
\hline$T$ & Temperature & \\
\hline & & \\
\hline
\end{tabular}

Table 1 Data for Computation.

\begin{tabular}{|c|c|c|c|c|}
\hline No & Segments & $\begin{array}{c}\text { Length } \\
\text { (km) }\end{array}$ & $\begin{array}{c}\text { Flowrate } \\
\text { (MMSCF/D) }\end{array}$ & $\begin{array}{c}\text { Elevation } \\
\text { (meter) }\end{array}$ \\
\hline 1 & A-B & 50 & 341 & 0 \\
2 & B-C & 75 & 341 & 100 \\
3 & C-D & 43.75 & 341 & 0 \\
4 & D-E & 62.5 & 841 & 100 \\
5 & E-F & 31.25 & 841 & 100 \\
6 & F-G & 62.5 & 841 & 400 \\
7 & G-H & 87.5 & 841 & 0 \\
8 & H-I1 & 125 & 841 & 400 \\
9 & I1-J1 & 75 & 841 & 0 \\
10 & J1-K1 & 50 & 841 & 0 \\
11 & K1-L1 & 18.75 & 841 & 0 \\
12 & L1-M1 & 25 & 841 & 0 \\
13 & M1-OF & 75 & 841 & 0 \\
14 & OF-SN & 470 & 841 & $(200)$ \\
\hline
\end{tabular}

Table 2 Summary of physical parameters, west scenario. 


\begin{tabular}{|c|c|c|c|c|}
\hline No & Segments & $\begin{array}{c}\text { Length } \\
(\mathbf{k m})\end{array}$ & $\begin{array}{c}\text { Flowrate } \\
\text { (MMSCF/D) }\end{array}$ & $\begin{array}{c}\text { Elevation } \\
\text { (meter) }\end{array}$ \\
\hline 1 & A-B & 50 & 341 & 0 \\
2 & B-C & 75 & 341 & 100 \\
3 & C-D & 43.75 & 341 & 0 \\
4 & D-E & 62.5 & 841 & 100 \\
5 & E-F & 31.25 & 841 & 100 \\
6 & F-G & 62.5 & 841 & 400 \\
7 & G-H & 87.5 & 841 & 0 \\
8 & H-I2 & 37.5 & 841 & 0 \\
9 & I2-J2 & 31.25 & 841 & 100 \\
10 & J2-K2 & 25 & 841 & 100 \\
11 & K2-L2 & 50 & 841 & 400 \\
12 & L2-M2 & 81.25 & 841 & 100 \\
13 & M2-N2 & 50 & 841 & 100 \\
14 & N2-O2 & 25 & 841 & 0 \\
15 & O2-OF & 37.5 & 841 & 0 \\
16 & OF-SN & 470 & 841 & $(200)$ \\
\hline
\end{tabular}

Table 3 Summary of physical parameters, east scenario.

Pipe specification is $\mathrm{X}-65$. Maximum discharge pressures are controlled not more than 1000 psia. Here we will compare the optimization result between Panhandle A and Panhandle B. The complete data of the pipeline network can be seen in table 2 and 3.

The results of numerical computation and analysis for East and West route will be presented in two forms, which are the optimum result and the practical result.

\subsection{Optimum Result}

The optimum result is directly obtained from numerical computation, as well as the number and the position of compressors. Here the compressors are placed in every node on the route and the process will eliminate unnecessary compressor in the certain position. At the end, we will obtain the optimum number of compressor in the certain position, beside the optimum diameter and horse power. The result of optimum condition can be seen in table 4 and 5 below.

Note that for both routes, the optimum results place several compressors in almost all nodes. This may not be practical in the field. Practical results which are preferable in reality are shown in the next section. 


\begin{tabular}{|c|c|c|c|c|c|c|c|}
\hline \multirow{2}{*}{$\begin{array}{c}\text { Data } \\
\text { Distance } \\
\text { (mile) }\end{array}$} & \multicolumn{6}{|c|}{ Optimization Result } & \multirow[b]{2}{*}{$\begin{array}{c}\text { Toll fee } \\
\text { (US\$MSCF) }\end{array}$} \\
\hline & $\begin{array}{l}\text { Flowrate } \\
\text { (MMSCFD) }\end{array}$ & $\begin{array}{l}\text { Outside } \\
\text { Diameter } \\
\text { (inch) }\end{array}$ & Real & $\begin{array}{l}\text { Pressure } \\
\text { psia) }\end{array}$ & $\begin{array}{l}\text { Thickness } \\
\text { (inch) }\end{array}$ & $\begin{array}{c}\text { Horse } \\
\text { Power } \\
\text { (HP) }\end{array}$ & \\
\hline 31 & 341 & 26 & 704 & -632 & 0.344 & 0 & 0.03 \\
\hline 46.5 & 341 & 24 & 935 & - 800 & 0.406 & 5,641 & 0.06 \\
\hline 27.125 & 341 & 28 & 950 & - 926 & 0.5 & 2,456 & 0.04 \\
\hline 38.75 & 841 & 36 & 926 & -841 & 0.625 & 0 & 0.02 \\
\hline 19.375 & 841 & 36 & 841 & -800 & 0.562 & 0 & 0.01 \\
\hline 38.75 & 841 & 34 & 971 & -849 & 0.625 & 6,711 & 0.03 \\
\hline 54.25 & 841 & 34 & 968 & $-\quad 852$ & 0.625 & 4,511 & 0.04 \\
\hline 77.5 & 841 & 36 & 948 & -760 & 0.625 & 3,693 & 0.06 \\
\hline 46.5 & 841 & 36 & 956 & -896 & 0.625 & 7,969 & 0.04 \\
\hline 31 & 841 & 36 & 896 & - 832 & 0.625 & 0 & 0.02 \\
\hline 11.625 & 841 & 36 & 832 & -807 & 0.562 & 0 & 0.01 \\
\hline 15.5 & 841 & 36 & 807 & - 773 & 0.562 & 0 & 0.01 \\
\hline 46.5 & 841 & 34 & 959 & -846 & 0.344 & 7,468 & 0.04 \\
\hline \multirow[t]{4}{*}{291.4} & 841 & 38 & 957 & $-\quad 350$ & 0.688 & 4,259 & 0.34 \\
\hline & & \multicolumn{2}{|l|}{$\begin{array}{l}\text { Annual Cost } \\
\text { (US\$/year) }\end{array}$} & \multicolumn{2}{|c|}{$205,570,700$} & & \\
\hline & & \multicolumn{2}{|c|}{$\begin{array}{l}\text { Total Toll fee } \\
\text { (US\$/MSCF) }\end{array}$} & \multicolumn{2}{|l|}{0.75} & & \\
\hline & & \multicolumn{2}{|c|}{$\begin{array}{l}\text { Present Value } \\
\text { (US\$) }\end{array}$} & \multicolumn{2}{|c|}{$1,535,499,000$} & & \\
\hline
\end{tabular}

Table 4 Optimum result for West Route, using Panhandle A equation.

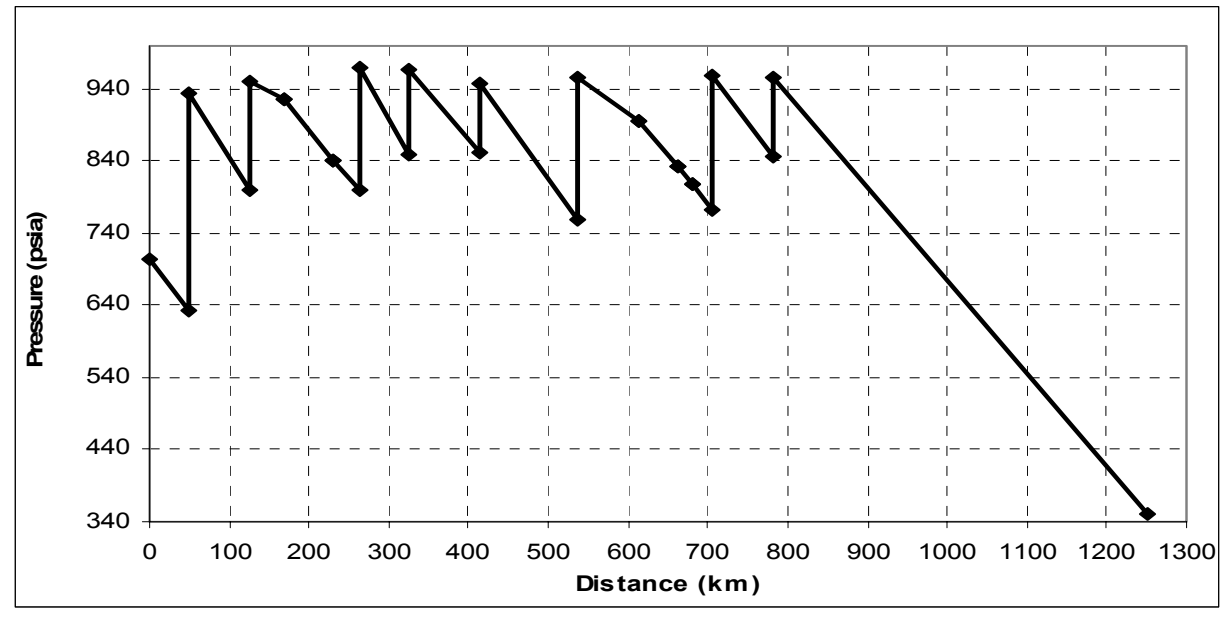

Figure 5 Pressure distribution for Optimum Result West Route. 


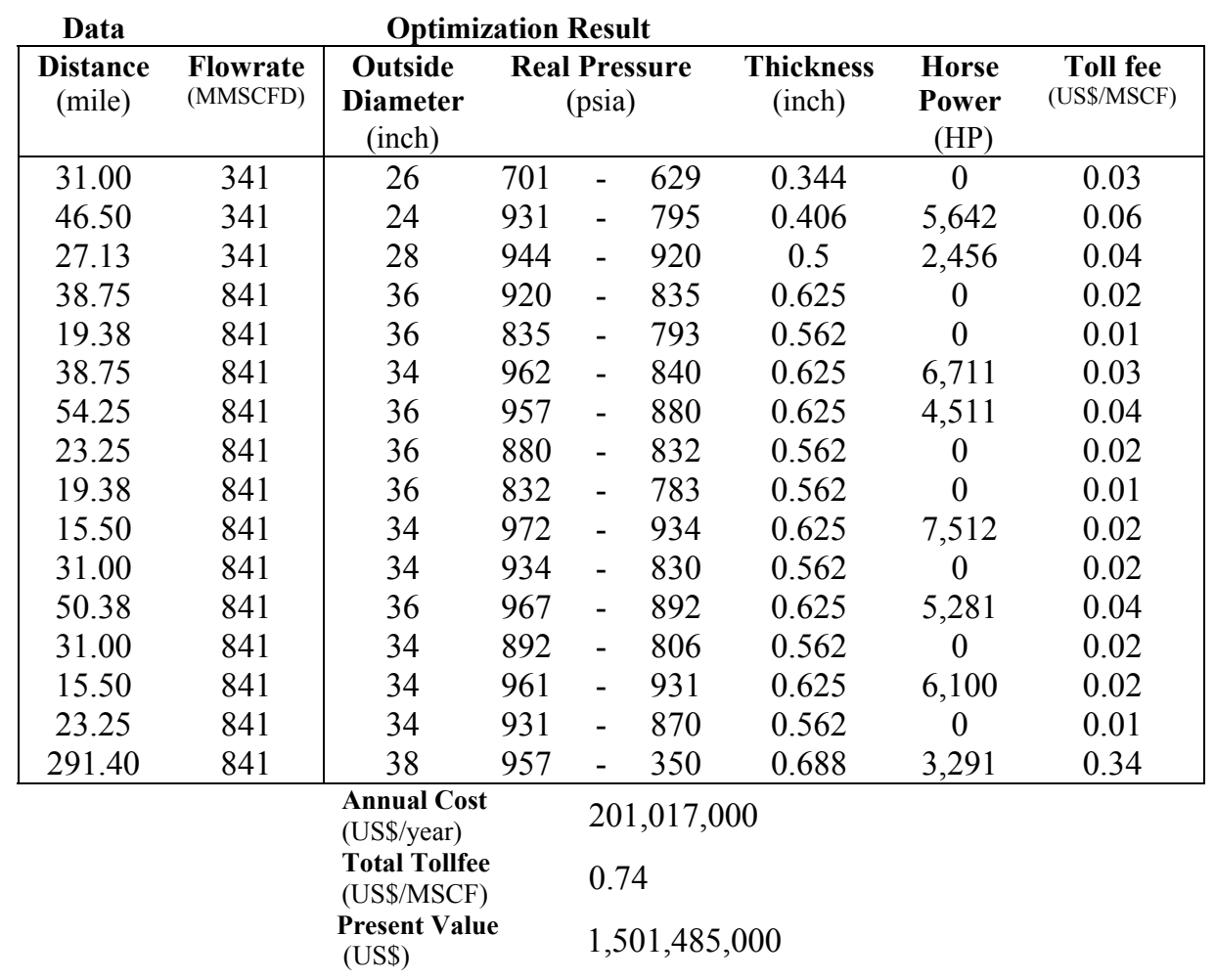

Table 5 Optimization result for East Route.

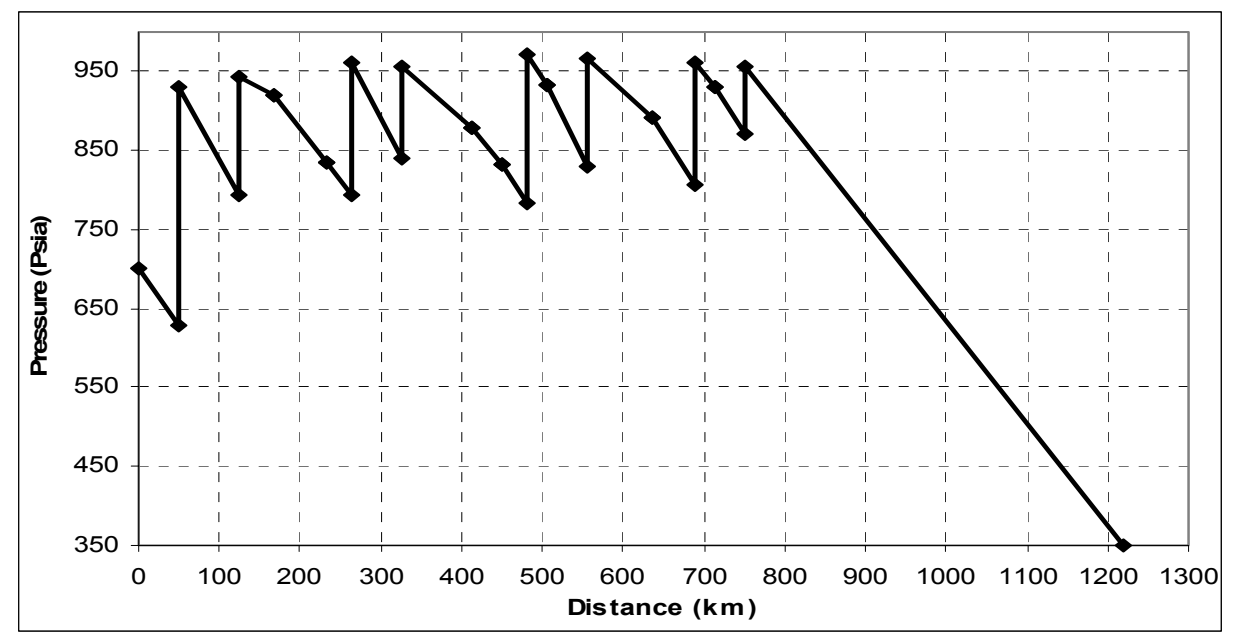

Figure 6 Pressure distribution for Optimum case East Route. 


\subsection{Practical Result}

The optimum result may not be practical and applicable in the real condition, because the positions of the compressors are not feasible for practical condition. Here the compressor positions are relocated (if necessary) in selected position or node, with the distance in between 150-200 kilometers each. The result can be seen in table 6 and 7 below.

Data

Optimization Result

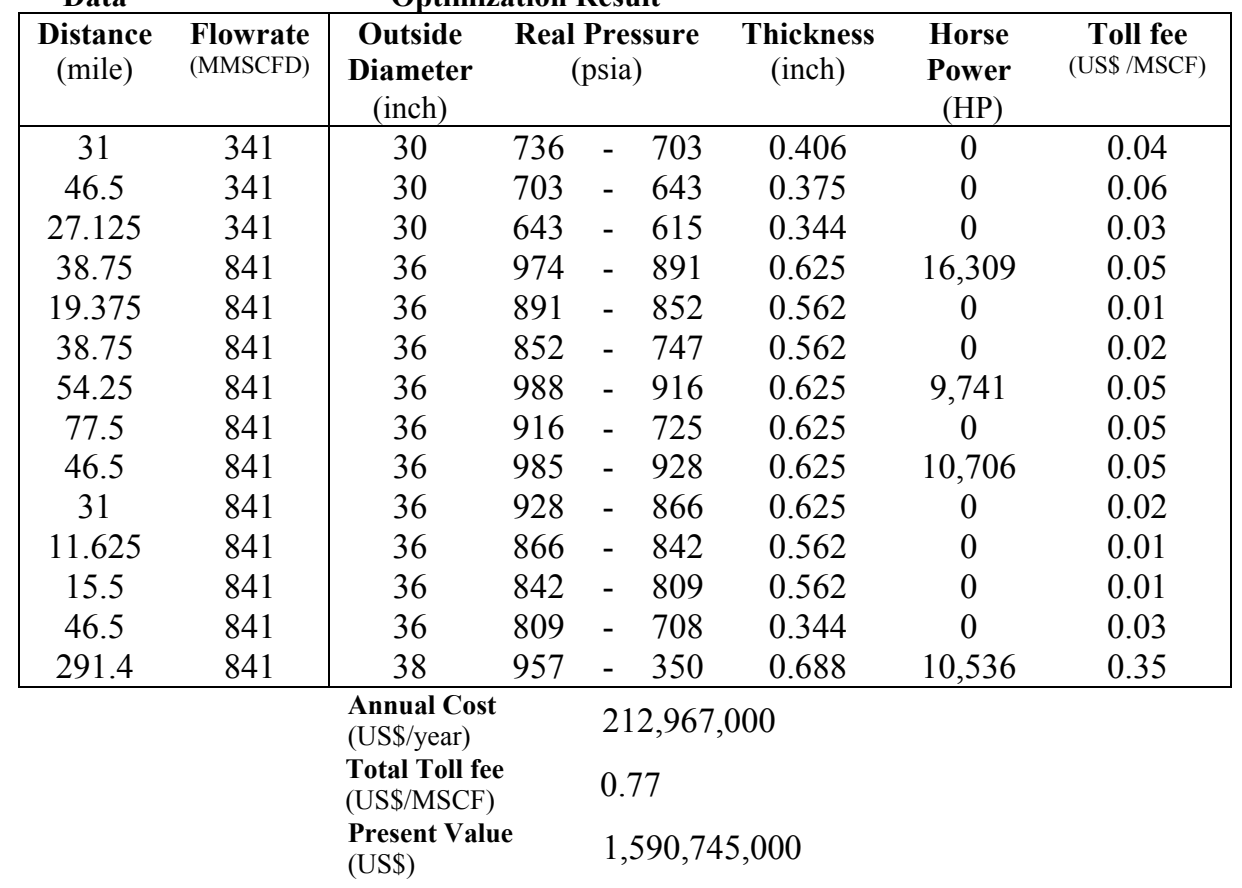

Table 6 Practical-Optimum result for West Route.

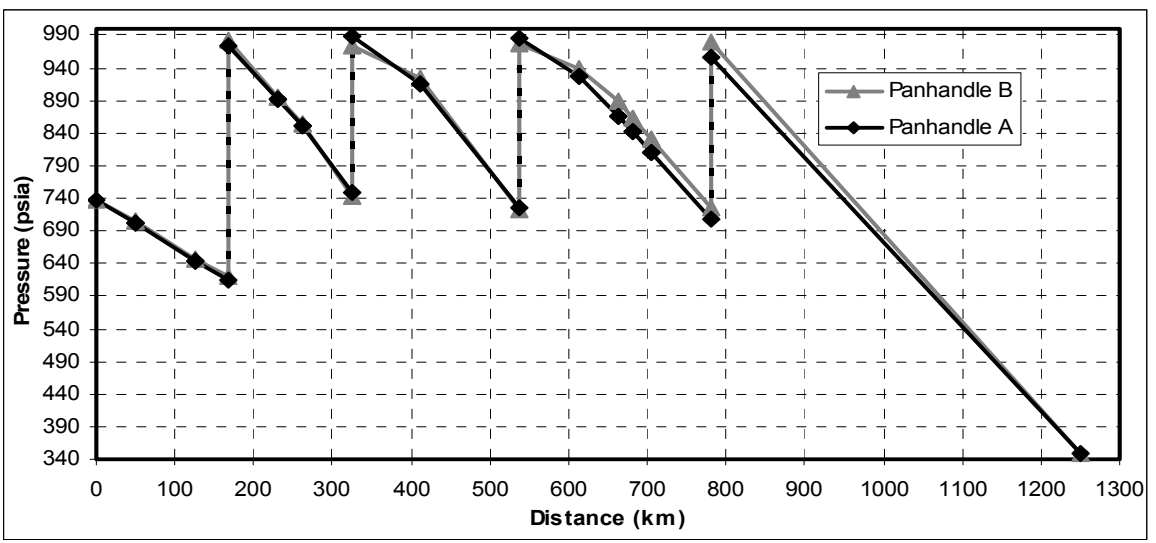

Figure 7 Pressure distribution for Practical-Optimum case West Route. 


\subsection{Analysis}

From section 7.1, we obtain the optimum result of SIJ pipeline network. The compressor is located in every node and the numerical process eliminates unnecessary compressor to obtain the optimum number of compressor. For the west route, from 14 compressor placed, the process decrease it into 8 compressor (table 4) and for east route, the number decreases from 16 into 8 compressor (table 5). However, in this case, the numbers of compressor still not suitable for practical utilization, because the distance of each compressor is not long enough. The diameter size is also obtained with various numbers, which make it not practical for real condition, such as if there is any maintaining process, cleaning process, etc.

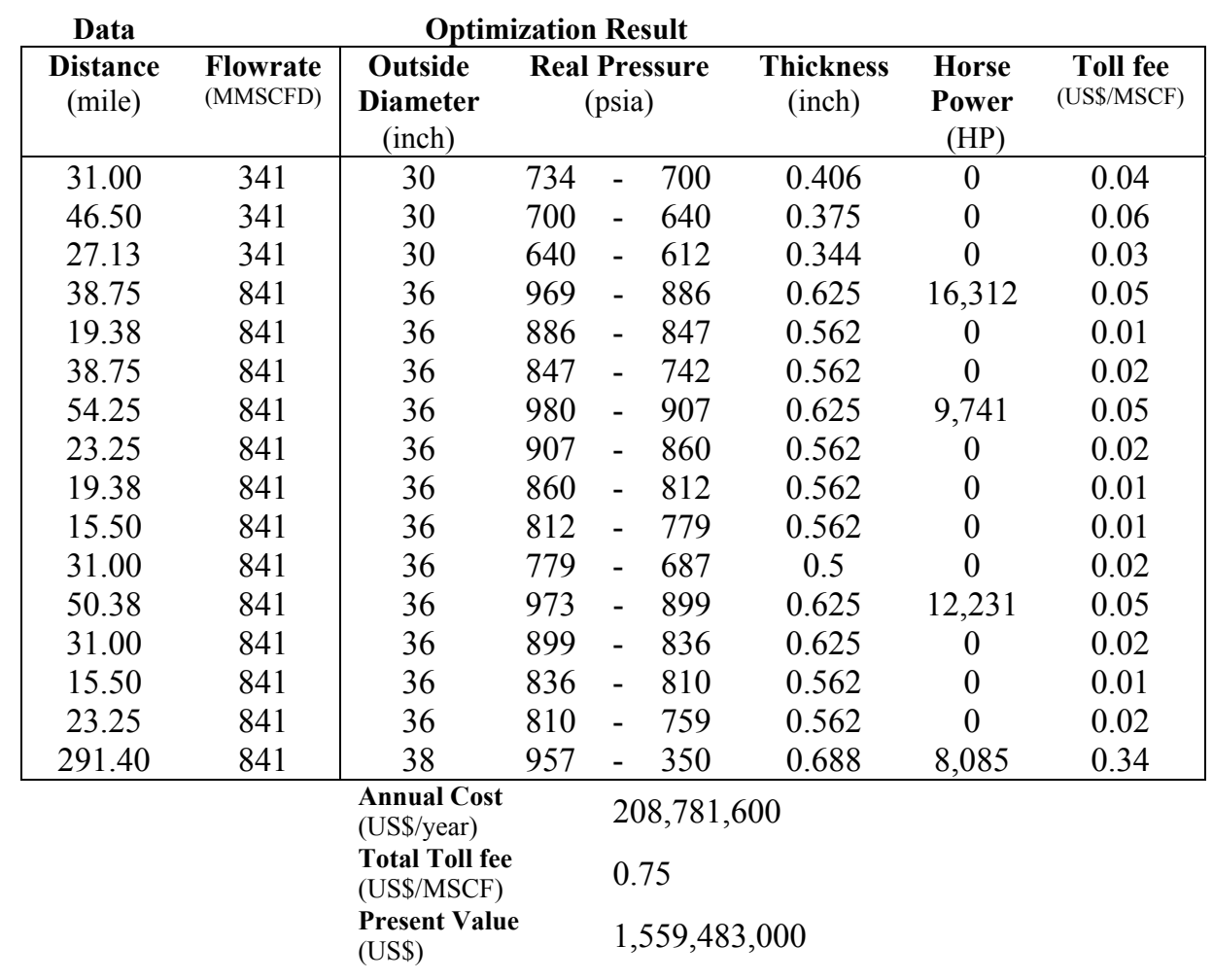

Table 7 Optimization-practical result for East Route.

The second result, which is shown in section 7.2, is rather more practical. Here the compressor placement only in 4 positions (table 6 , table 7), with each distance in between 150-250 km. Here, for both route, the diameter results are obtained more uniformly than previous case. For the onshore pipeline, the diameter is 30 and 36 inches. This is caused by the differences of the flowrate in those pipelines. 


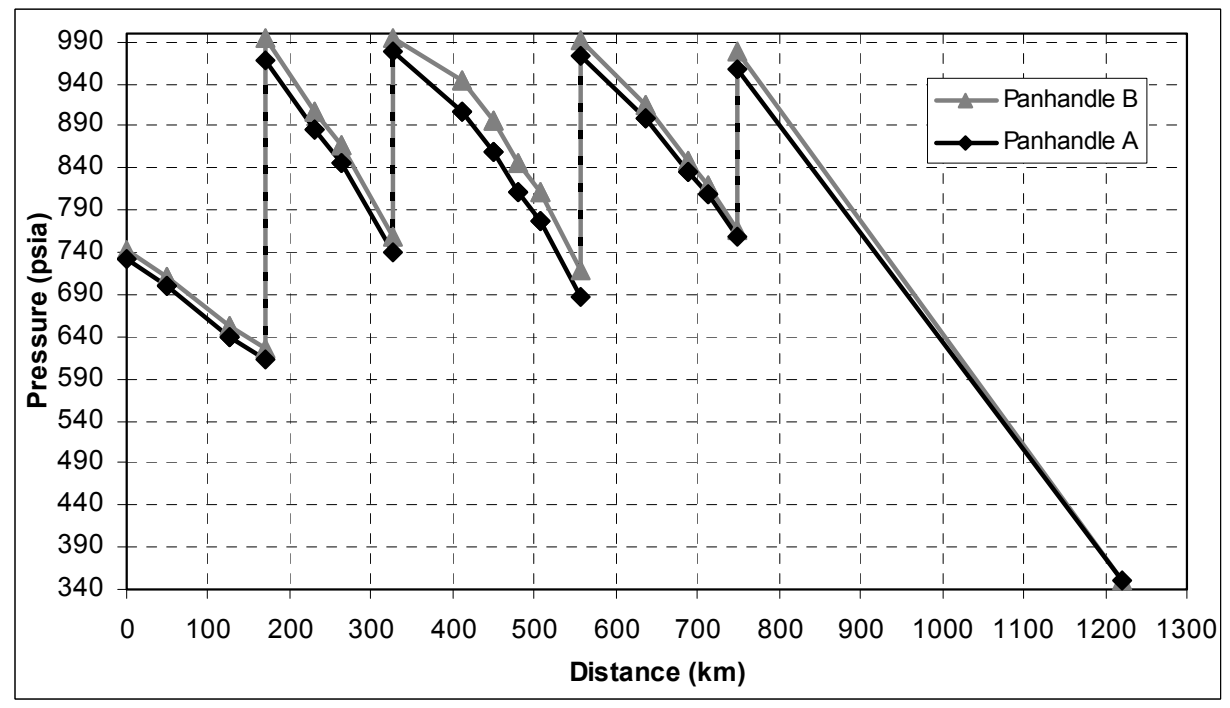

Figure 8 Pressure distribution for Practical-Optimum case East Route.

The offshore pipeline is about $470 \mathrm{~km}$, and only uses 1 compressor with discharge pressure at 1000 psia. This condition happens because it is not preferable to put a compressor station in the middle of the ocean. Due this condition, the pipe diameter on the offshore area has to be larger than the onshore pipeline diameter, which is 38 inches.

\section{Sensitivity Analysis}

A sensitivity analysis is usually performed to observe the changes of variable of interest due to the changes of parameter. Here we make some sensitivity analysis for toll fee, with respect to flow rate. The result can be seen in figure 7.

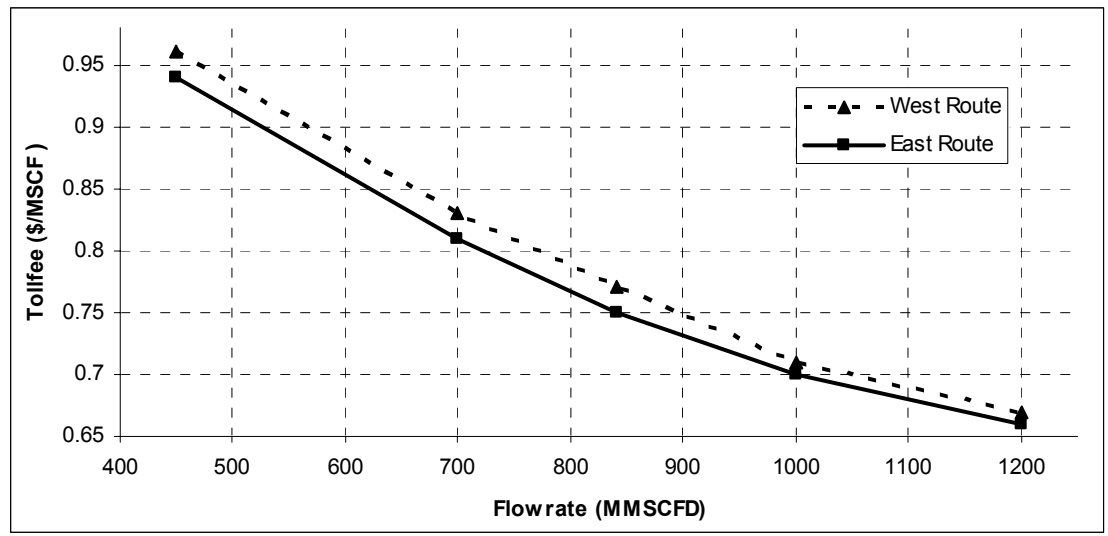

Figure 9 Toll fee sensitivity analysis. 
The optimization result is also giving a different result of diameter. The larger flow rate implies the larger diameter, but gives smaller toll fee value.

\section{Conclusion}

We have presented the optimum SIJ transmission (east and west) networks resulting from minimization of total cost function subject to constraints in the forms of flow equation in each segment pipe, maximum strength of pipe and additional constraints related to compressor. The computations are performed with fourth order Runge Kutta method. The optimum diameters resulting from the continuous optimization are then being used to find the closest sizes available in the market. Results indicate that the east route is relatively less expensive than the west route.

\section{Acknowledgment}

The authors would like to thank the Research Consortium OPPINET for funding the research.

\section{References}

1. De Wolf, D., Smeers, Y., Optimal Dimensioning of Pipe Networks with Application to Gas Transmission Network, Operation Research v. 44, 1996, 596-608.

2. De Wolf, D., Smeers, Y., The Gas Transmission Problem Solved by an Extension of the Simplex Algoritm, to appear in Management Science.

3. Osiadacz, A.J., Gorecki, M., Optimization of Pipe sizes for Distribution Gas Network Design, PSIG 9511, 1995.

4. Arsegianto, Soewono, E., Apri, M., Non-Linear Optimization Model for Gas Transmission System: A Case of Grissik - Duri Pipeline, to appear in SPE 80506.

5. Siregar, S., Soewono, E., Mucharam, L., Sidarto, K.A., Arsegianto, Chaerani, D., Mubassiran, Research on Gas Pipeline Network Modelling In Order to Anticipate Development of National Gas Pipeline Network (Indonesian), Proc. Lokakarya Gas II, PERTAMINA, 2001, 219-224.

6. Siregar, S., Soewono, E., Mucharam, L., Putra, Satya A., Udayana, W.T., Wangsadiputra, A., Siregar, D., Optimization of Gas Pipeline Network in Indonesian Gas Field, presented in INFORMS Annual Meeting, San Jose, USA, Nov 2002. 
7. Ikoku, Chi U., Natural Gas Production Engineering, J. Wiley, 1984.

8. Xue, G., Lillys, T.P., Dougherty, D.E., Computing the Minimum Cost Pipe Networks Interconnecting One Sink and Many Sources, SIAM J. OPTIM Vol. 10, No. 1, pp 22 42, 1999.

9. Soewono, E, Siregar, S., Widiasri, I. S., Ariani, N., Optimization for Large Gas Transmission Network Using Least Difference Heuristic Algorithm, will be presented in International Conference 2003 on Mathematics and its Application, Yogyakarta, 14-17 July 2003.

10. Arnold, K., Steward, M., Surface Production Operation vol. 1, Gulf Publishing Co., Houston, 1986. 